\title{
Review Article \\ Electrochemical Biosensors Based on Nanostructured Carbon Black: A Review
}

\author{
Tiago Almeida Silva, ${ }^{1}$ Fernando Cruz Moraes, ${ }^{1}$ \\ Bruno Campos Janegitz, ${ }^{2}$ and Orlando Fatibello-Filho ${ }^{1}$ \\ ${ }^{1}$ Department of Chemistry, Federal University of São Carlos, Rod. Washington Luís, Km 235, 13560-970 São Carlos, SP, Brazil \\ ${ }^{2}$ Department of Nature Sciences, Mathematics and Education, Federal University of São Carlos, Rod. Anhanguera, \\ Km 174, 13600-970 Araras, SP, Brazil \\ Correspondence should be addressed to Bruno Campos Janegitz; brunocj@ymail.com
}

Received 29 March 2017; Accepted 11 May 2017; Published 5 June 2017

Academic Editor: Deepak Ganta

Copyright (c) 2017 Tiago Almeida Silva et al. This is an open access article distributed under the Creative Commons Attribution License, which permits unrestricted use, distribution, and reproduction in any medium, provided the original work is properly cited.

\begin{abstract}
Carbon black $(\mathrm{CB})$ is a nanostructured material widely used in several industrial processes. This nanomaterial features a set of remarkable properties including high surface area, high thermal and electrical conductivity, and very low cost. Several studies have explored the applicability of CB in electrochemical fields. Recent data showed that modified electrodes based on CB present fast charge transfer and high electroactive surface area, comparable to carbon nanotubes and graphene. These characteristics make CB a promising candidate for the design of electrochemical sensors and biosensors. In this review, we highlight recent advances in the use of $\mathrm{CB}$ as a template for biosensing. As will be seen, we discuss the main biosensing strategies adopted for enzymatic catalysis for several target analytes, such as glucose, hydrogen peroxide, and environmental contaminants. Recent applications of CB on DNA-based biosensors are also described. Finally, future challenges and trends of CB use in bioanalytical chemistry are discussed.
\end{abstract}

\section{Introduction}

Since the 1990s, after the carbon nanotubes properties reported by Iijima [1], the interest in conductive carbon nanostructured materials has been increasing in different areas, for example, medicine, food, and environment. Nanostructured carbonaceous materials should present some important characteristics, such as high surface area and electrocatalysis. Over the years, carbon nanotubes and graphene have been applied successfully in the development of electrochemical sensors in analytical chemistry $[2,3]$. Carbon black $(\mathrm{CB})$ is a conductive low cost nanomaterial made by petroleum products combustion, which presents defect sites. Today, CB represents an alternative material to be used for the development of electrochemical devices, specially sensors and biosensors, in order to detect several analytes. Usually, some research groups have used CB in the fabrication of electrodes based on thin films and composites. This nanomaterial can be easily modified with other materials, as metallic nanoparticles [4] and polymers [5], as reported by Arduini and coauthors [6], which constructed an interesting screen-printed electrode modified with CB for electroanalysis proposes.

$\mathrm{CB}$ is comparable to other well-explored carbon nanomaterials, including graphene, carbon nanotubes (singlewalled carbon nanotubes (SWCNTs) and multiwalled carbon nanotubes (MWCNTs)), fullerene $\left(\mathrm{C}_{60}\right)$, and single-walled carbon nanohorns (SWCNHs). Considering the electrochemical sensing of the neurotransmitter dopamine by using different carbon nanomaterials, CB has been highlighted an excellent modifier. In this context, by adopting similar electrode modification procedures, dopamine electrochemical sensors based on glassy carbon electrode (GCE) modified with graphene, carbon nanotubes, $\mathrm{C}_{60}$, SWCNHs, and $\mathrm{CB}$ were reported by Sheng et al. [7], Habibi and Pournaghi-Azar [8], Zhang et al. [9], Zhu et al. [10], and Vicentini et al. [11]. In all mentioned works, by using voltammetric techniques, wide linear concentration ranges at submicromolar levels 
TABLE 1: Physical and chemical properties of carbon black nanomaterial.

\begin{tabular}{|c|c|}
\hline Property & Data \\
\hline Shape & Spherical particles strongly bonded to form aggregates \\
\hline Particle size $(\mathrm{nm})$ & 3.0 to 100 \\
\hline Electrical conductivity $\left(\mathrm{S} \mathrm{m}^{-1}\right)[18]$ & 1.0 to $2.0 \times 10^{3}$ \\
\hline Thermal conductivity $\left(\mathrm{W} \mathrm{m}^{-1} \mathrm{~K}^{-1}\right)$ [19] & 0.2 to 0.3 \\
\hline Tensile strength $(\mathrm{MPa})^{[\mathrm{a}]}[20]$ & 20 to 50 \\
\hline Surface area $\left(\mathrm{m}^{2} \mathrm{~g}^{-1}\right)[21,22]$ & 15 to 1000 \\
\hline Young's modulus $\left(\mathrm{MN} \mathrm{m}^{-2}\right)^{[\mathrm{a}]}[23]$ & 1 to 50 \\
\hline Poisson modulus ${ }^{[\mathrm{a}]}[23]$ & 0.494 to 0.500 \\
\hline Hydrodynamic diameters $(\mathrm{nm})^{[\mathrm{b}]}[24]$ & 794 \\
\hline$Z$-potential values, $\zeta(\mathrm{mV})^{[\mathrm{b}]}[24]$ & +29.4 \\
\hline
\end{tabular}

were obtained, as well as the following limits of detection: $2.5 \times 10^{-7} \mathrm{~mol} \mathrm{~L}^{-1}$ (graphene sensor) [7], $3.1 \times 10^{-7} \mathrm{~mol} \mathrm{~L}^{-1}$ (carbon nanotubes sensor) [8], $7.0 \times 10^{-8} \mathrm{~mol} \mathrm{~L}^{-1}\left(\mathrm{C}_{60}\right.$ sensor) [9], $6.0 \times 10^{-8} \mathrm{~mol} \mathrm{~L}^{-1}$ (SWCNHs sensor) [10], and $5.24 \times$ $10^{-8} \mathrm{~mol} \mathrm{~L}^{-1}$ (CB sensor) [11]. In addition, it is interesting note that, using the $\mathrm{CB}$ sensor, the dopamine was simultaneously determined in the presence of ascorbic acid, paracetamol, and uric acid. Therefore, the simultaneous determination of this quaternary mixture of analytes in biological fluids via electrochemical tools was an analytical challenge solved by using a $\mathrm{CB}$ sensor.

In another exciting work from Compton group [12], the electrochemical sensing features of MWCNTs and CBbased sensors toward nicotine determination were compared. By applying adsorptive stripping voltammetry (AdSV) the MWCNTs and CB sensors provided limits of detection for nicotine of $5.0 \mu \mathrm{mol} \mathrm{L}^{-1}$ and $2.0 \mu \mathrm{mol} \mathrm{L}^{-1}$, respectively. Therefore, an improvement in the voltammetric response was recorded using the $\mathrm{CB}$ modified electrode, which was observed significantly lower background signal and larger Faradaic currents achieved using this nanomaterial. In terms of electrochemical biosensing, the same comparative approach between carbon nanomaterials could be carried out considering an amperometric glucose biosensor. We will provide this detailed comparison in the following sections.

Electrochemical biosensors are selective devices using a biological recognition element immobilized on the transducer $[14,15]$. Biosensors are able to provide quantitative or semiquantitative analytical information, which transforms the biorecognition reaction of the analyte to a measurable signal. These devices may be applied in different areas, such environmental, medical, biological, pharmaceutical, or industrial $[14,15]$. In order to obtain a sensitive electrochemical biosensor based on $\mathrm{CB}$, several architectures can be obtained in the preparation of the electrode surface such as monolayer, multilayers, and thin films. In the course of this article we will present a discussion about $\mathrm{CB}$ and its application in electrochemical biosensing, focusing on the surface architectures, materials, and preparation. Finally, we will present the prospects and future applications of $\mathrm{CB}$ in electroanalytical chemistry.

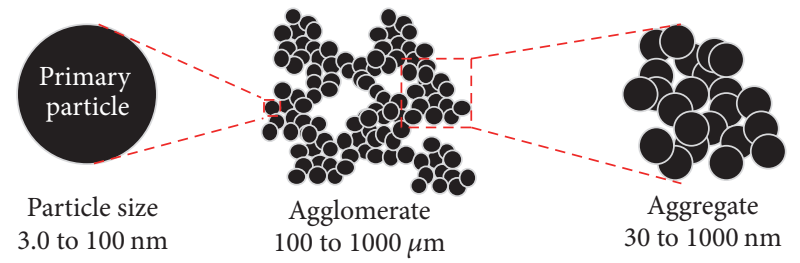

FIGURE 1: Schematic representation of nanometer-scale morphology of CB.

\section{Considerations on Carbon Black Nanomaterial}

$\mathrm{CB}$ is used in several areas of modern life, considering the range of relevant physical and chemical features, which are showed in Table 1. The most cited applications including its use in printer ink, reinforcements for rubber, active agent in electrically conductive plastic, and pigments in paints. Additionally, $\mathrm{CB}$ can be used as coatings, papers ink and cosmetics. $\mathrm{CB}$ can be produced by the following processes: "furnace," "channel," and "acetylene" [16, 17]. The most useful process is the "furnace," which produces more than $80 \%$ of the $\mathrm{CB}$ in the world. Depending on the process, $\mathrm{CB}$ can present different characteristics. In special, "acetylene" process produces small CB particles with high complexity of the agglomerates and higher graphitic content than those produced by furnace process.

CB primary particle is formed by elemental carbon arranged in fine particles, which has an amorphous and quasigraphitic structure. The average $\mathrm{CB}$ particle size ranges from 3.0 to $100 \mathrm{~nm}$. However, one of the characteristics of CB is the formation of aggregates nanostructures, by presenting semispherical groupings. Moreover, these aggregates groups, with a distinctly long dimension, can form agglomerates. Figure 1 was adapted from the Kohjiya et al. [25] article and schematically displays the CB particle, CB aggregates, and agglomerates. Figure 2 shows typical scanning (SEM) and transmission (TEM) electron microscopy images recorded for $\mathrm{CB}$ particles. In this case, a VXC72R CB type was deposited on the GCE substrate [11]. From that, it is possible 


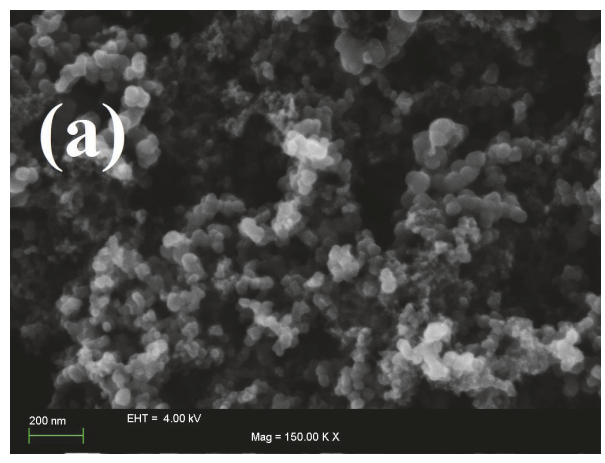

(a)

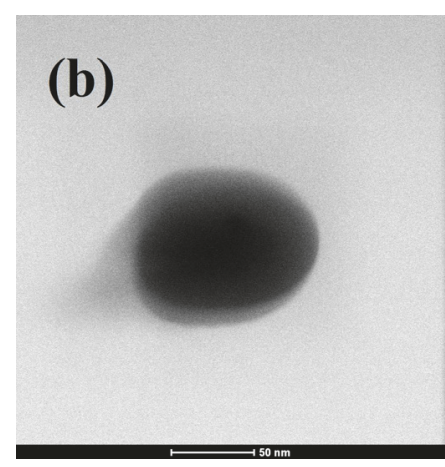

(b)

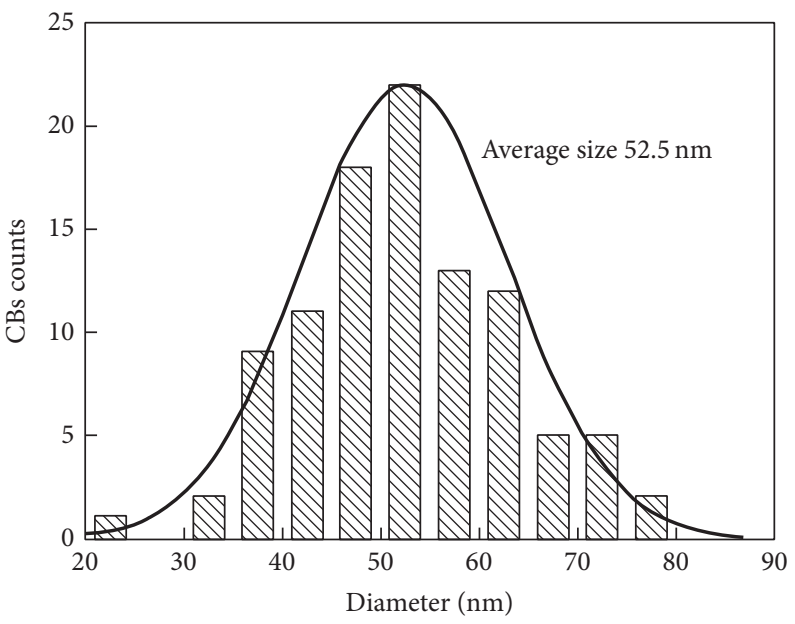

(c)

FIGURE 2: (a) SEM images of CB nanostructure, (b) HR-TEM micrographs of CB nanostructure, and (c) the corresponding histogram of the CBs diameters (the solid line corresponds to the Gaussian fit) (reproduced with permission of Elsevier [11]).

to verify the morphological aspects that confirm the scheme shown in Figure 1. CB formed porous structure based on beads (Figure 2(a)) and the spherical particles (Figure 2(c)) present an average diameter of $52.5 \mathrm{~nm}$ [11].

$\mathrm{CB}$ prepared from heat treatment up to $700^{\circ} \mathrm{C}$ [26] may increase the number of conjugated carbons in the $\mathrm{sp}^{2}$ hybridization, leading to a progressive increase in the conductivity of this material. This factor can be associated with electrons with delocalized $\pi$-bonds that are available for charge storage [27]. In addition, oxygenates groups are preferentially formed at the edges of the graphite-like microcrystallites [28]. This behavior may be interesting to create an environment to immobilize organic molecules, such as enzymes and other biological material. The presence of a great number of $\mathrm{sp}^{2}$ edge plans, the oxygenate species displayed over the $\mathrm{CB}$ particles, and the $\mathrm{CB}$ aggregation forms are intrinsic linked to the $\mathrm{CB}$ electrochemical behavior. These characteristics show that CB has the ability to intercalate ions on graphite layers [29], which affects electrical conduction between particles by tunneling [30] and the surface reaction. In particular, the surface area, the number of edges planned, and the structural defects depend on the synthesis or functionalization processes, which create several functional groups that can be useful for the immobilization of various species, such as enzymes [31], genetic material [32], antibodies [33], and nanoparticles [4]. The sum of structural and electrical/electronic characteristics, ability to produce stable dispersion without the need for sophisticated procedures, and the fact that it is an extremely cheap material make the $\mathrm{CB}$ an interesting nanostructured material for the development of electrochemical devices for sensing and biosensing.

\section{Biosensors Based on Nanostructured Carbon Black}

$\mathrm{CB}$ is a relatively novel material in the field of electroanalytical chemistry. The first studies related to investigation of $\mathrm{CB}$ as modifier for sensors preparation were reported only in the last decade. One of the highlight pioneering works was the electrochemical sensors reported by Dang et al. [34] and Zhang $[35,36]$. In these cases, CB was designated with acetylene black for the voltammetric sensing of tetracycline, colchicine, and rutin. The origin and/or type of CB can affect directly the electroanalytical performance of the designed electrochemical (bio)sensor. In this sense, our research group 
TABLE 2: Electrochemical parameters of GCE and CB modified electrode.

\begin{tabular}{lccccccrr}
\hline \multirow{2}{*}{ Electrode } & \multicolumn{9}{c}{ Electrochemical parameter } \\
& $I_{\mathrm{pa}}(\mu \mathrm{A})$ & $I_{\mathrm{pc}}(\mu \mathrm{A})$ & $I_{\mathrm{pa}} / I_{\mathrm{pc}}$ & $E_{\mathrm{pa}}(\mathrm{mV})$ & $E_{\mathrm{pc}}(\mathrm{mV})$ & $\Delta E_{p}(\mathrm{mV})$ & $E_{1 / 2}(\mathrm{mV})$ & $k^{0}\left(\mathrm{~cm} \mathrm{~s}^{-1}\right)$ \\
\hline Bare GCE & 26.0 & -26.4 & 0.98 & 290 & 197 & 93 & 234 & $1.02 \times 10^{-3}[72]$ \\
CB-GCE $^{[\mathrm{a}]}$ & 43.8 & -43.6 & 1.00 & 272 & 206 & 66 & 211 & $9.26 \times 10^{-2}[37]$ \\
\hline
\end{tabular}

${ }^{[a]}$ GCE modified with CB nanoparticles confined within a cross-linked chitosan film.

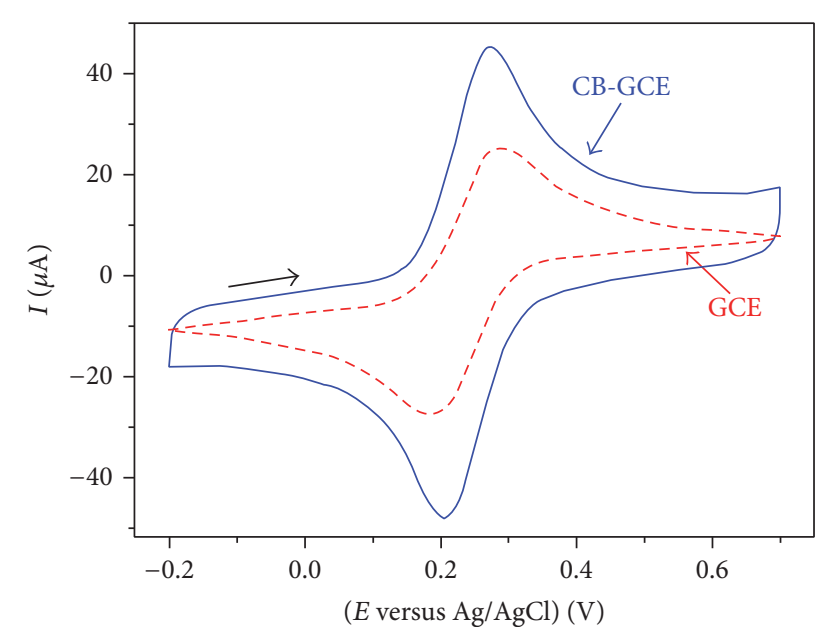

FIGURE 3: Cyclic voltammograms obtained for a $1.0 \times 10^{-3} \mathrm{~mol} \mathrm{~L}^{-1}$ $\mathrm{K}_{3} \mathrm{Fe}(\mathrm{CN})_{6}$ in $0.1 \mathrm{~mol} \mathrm{~L}^{-1} \mathrm{KCl}$ solution using a bare GCE and a CB$\mathrm{GCE}$. Scan rate $=100 \mathrm{mV} \mathrm{s}^{-1}$. Black arrow is the scan direction.

reported recently a complete study about the electroanalytical performance of GCE modified with different CB structures [37]. The electrochemical features toward inorganic redox probes and biologically relevant molecules using as modifier the following kinds of CBs were evaluated: VXC72R, BP4750, and E2000. From these studies, VXC72R CB promoted remarkable properties in contrast with those recorded using BP4750 and E2000 CB. The properties of this low cost material include fast charge transfer kinetics and high analytical sensitivity. Therefore, the identification of the appropriated supplier and kind of $\mathrm{CB}$ is an important factor in the preparation of high analytical performance CB-based electrochemical (bio)sensing. CB powder could be purchased from different commercial sources. In the case of our works, VXC72R CB of excellent performance for electrochemical sensing was kindly supplied by $\mathrm{Cabot}^{\circledR} \mathrm{Corporation}$ The cyclic voltammograms recorded for a bare GCE and a GCE modified with $\mathrm{CB}$ in $0.1 \mathrm{~mol} \mathrm{~L}^{-1} \mathrm{KCl}$ solution containing 1.0 $\times 10^{-3} \mathrm{~mol} \mathrm{~L}^{-1}$ redox probe $\left[\mathrm{Fe}(\mathrm{CN})_{6}{ }^{3-/ 4-}\right]$ are presented in Figure 3. From these voltammograms, a set of electrochemical parameters were recorded and organized in Table 2. The anodic $\left(I_{\mathrm{pa}}\right)$ and cathodic $\left(I_{\mathrm{pc}}\right)$ peak currents increased close to $70 \%$ after the modification, demonstrating the increase of electroactive surface area from CB incorporation over GCE surface. The ratio between $I_{\mathrm{pa}}$ and $I_{\mathrm{pc}}$ components $\left(I_{\mathrm{pa}} / I_{\mathrm{pc}}\right)$ was equal to 1.0 on the CB-GCE, which is a feature of the excellent reversibility of the studied redox probe. Considering the anodic $\left(E_{\mathrm{pa}}\right)$ and cathodic $\left(E_{\mathrm{pc}}\right)$ peak potentials, both anodic and cathodic peaks suffered a shift of potential in the CB-GCE case. From that, the peak-to-peak potential $\left(\Delta E_{p}\right)$ separation decreased from $93 \mathrm{mV}$ (GCE) to $66 \mathrm{mV}$ (CB-GCE). The decrease of $\Delta E_{p}$ indicates the enhanced charge transfer kinetic on the modified GCE. To prove this statement, the heterogeneous charge transfer rate constant $\left(k^{0}\right)$ for both electrodes was estimated and the obtained values are also shown in Table 2 . As can be seen, the $k^{0}$ constant increased $\approx 90$ times after the GCE modification with $\mathrm{CB}$ nanoparticles. All these data help to prove the excellent electrochemical behavior of CB nanoparticles, making it an exciting alternative carbon nanomaterial for construction of electrochemical sensors and biosensors. Currently, the use of $\mathrm{CB}$ for sensing purposes involves the electrochemical determination of pharmaceutical $[4,34-36,38-43]$, environmental contaminants [44-57], food additives [58-61], biomolecules [46, 62-71], and nicotine [12].

The use of CB in the manufacture of sensors is a theme in full development, and design of biosensors based on CB is a recent research topic. Table 3 lists the biosensors based on $\mathrm{CB}$ reported up to date. Electrochemical biosensors can be constructed exploring different biological events in according to the target analyte and biological recognition element, ranging from biocatalytic assays (enzymatic biosensors) [73] to affinity assays (genosensors and immunosensors) [74, 75]. In analyzing Table 3, it is evident that CB has been mainly applied for enzymatic biosensors.

Glucose enzymatic biosensing is a research topic that has been explored widely in the literature, due to the relevance of continuous diabetes monitoring [88]. The use of $\mathrm{CB}$ as a carbon support for immobilization of glucose oxidase was investigated by Xiao-He et al. [82]. The better approach for preparation of the biosensor using poly(sodium 4-styrenesulfonate) (PSS) grafted on the CB surface (CB-gPSS) was studied. The obtained results demonstrated that CB-g-PSS showed a good environment for glucose oxidase immobilization; however, selectivity and applicability tests were not provided. Carbon nanomaterials are widely explored to design biosensors based on glucose oxidase. Thus, it is an interesting approach to provide a comparison of analytical features recorded by using biosensors for glucose constructed with carbon nanomaterials, in order to verify the real advantages of low cost and widely available $\mathrm{CB}$ nanoparticles.

Table 4 shows a comparison of the analytical features of glucose oxidase (GOx) biosensors designed with SWCNTs, MWCNTs, $\mathrm{C}_{60}$, pristine graphene, graphene oxide (GO), reduced graphene oxide (RGO), SWCNHs, and $\mathrm{CB}$. The great part of works explored direct electron transfer (DET) between GOx enzyme and the nanostructured electrode surface. In these cases, a typical redox process is verified for 


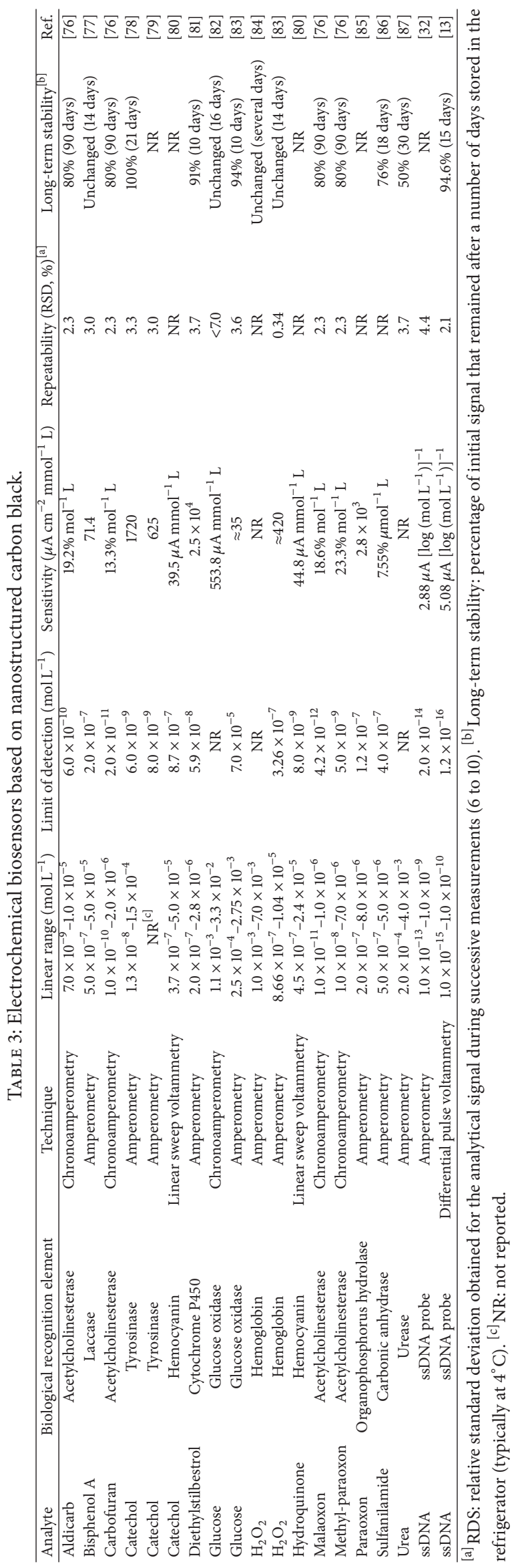




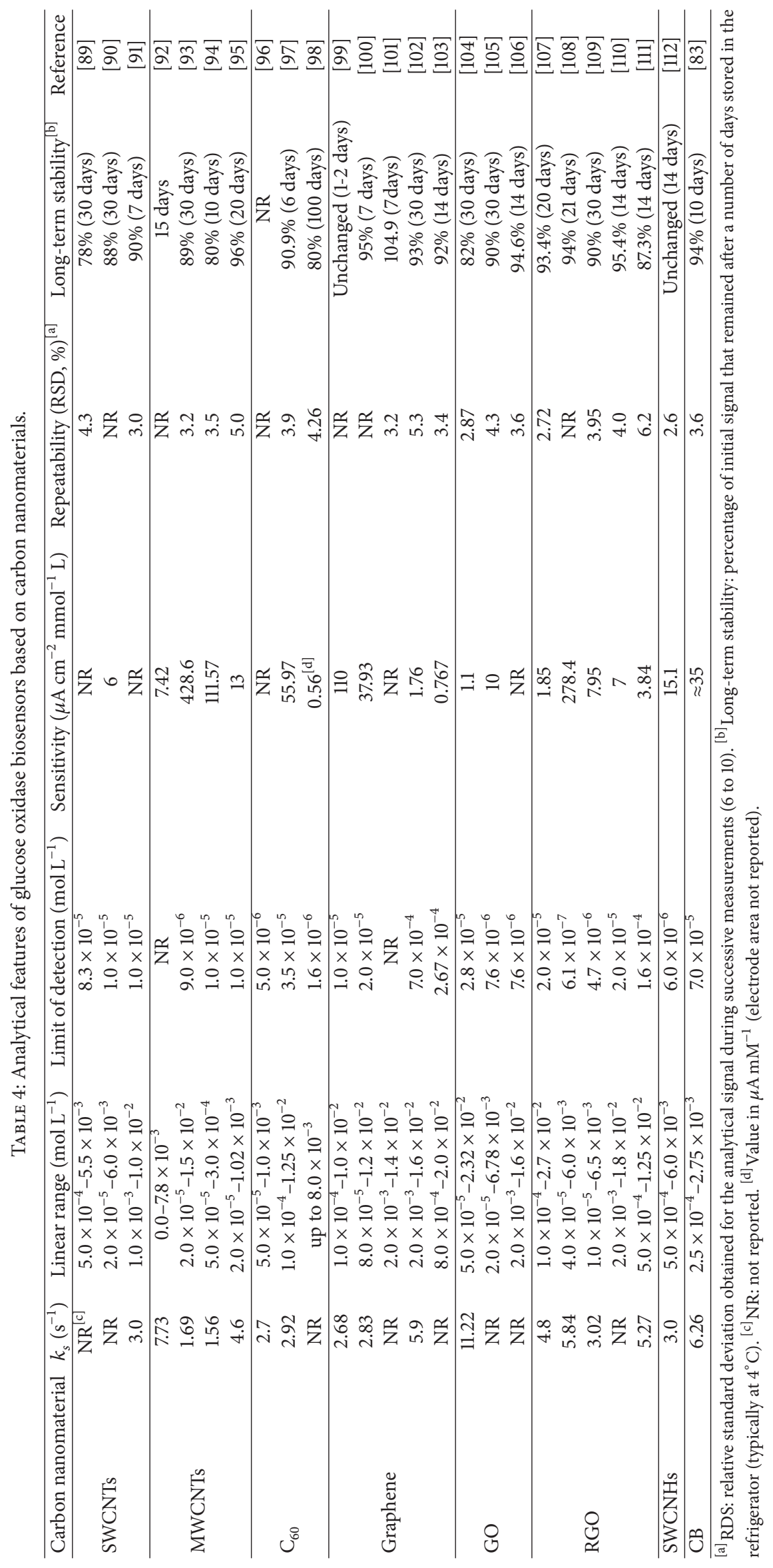


the biosensor response in buffer solution, which is attributed to the enzyme active centre. From cyclic voltammetric assays conducted at different scan rates, the authors stated that this process is controlled by the redox monolayer species adsorbed on the electrode surface. Using Laviron's equation the respective heterogeneous electron transfer rate constants $\left(k_{s}\right)$ were predicted and the obtained values are showed in Table 4. Therefore, this constant provides information about the electron transfer kinetic between immobilized GOx and electrode surface. CB nanoparticles were able to ensure a fast DET, with $k_{s}$ constant higher than those obtained using SWCNTs, MWCNTs, graphene, GO, RGO, and SWCNHs with only two exceptions among twenty-five revised works. From an analytical point of view, the CB-based GOx biosensor showed comparable linear range and limit of detection. In some cases, it is recorded limits of detection at micromolar levels. However, it should be observed that the glucose concentration in human blood is typically located in the millimolar range and, therefore, the linear range and limit of detection provided by the CB biosensor are adequate. A very important analytical parameter is the sensitivity. In this case, the most sensitive biosensors are those designed with MWCNTs, $\mathrm{C}_{60}$, and RGO. On the other hand, the sensitivity of CB biosensor is higher than graphene biosensor and presented a high sensitivity than several biosensors constructed with SWCNTs, MWCNTs, pristine graphene, GO, RGO, and SWCNHs. Besides that, from repeatability studies, low relative standard deviations (RSD) were obtained for the biosensor response during consecutive measurements in all the cases. The long-term stability was evaluated as being the percentage of signal variation after some days of storing in a refrigerator at $4^{\circ} \mathrm{C}$. There is not a standard in the works in terms of number of storing days and, in general, the biosensors maintained its initial response after many days, in special, for the CB biosensor case, which maintained $94 \%$ of its initial signal after ten days of storing.

The determination of the content of urea in milk samples, phenolic compounds in olive oil samples, and bisphenol $\mathrm{A}$ in tomato juice samples was interesting applications in the scenario of food analysis investigated by Laurinavicius et al. [87], Nadifiyine et al. [78], and Cammarota et al. [77], respectively. In the work proposed by Laurinavicius et al. [87], a CB paste electrode was modified with a flexible membrane based on terylene precoated with polyvinyl alcohol (PVA-T) containing the immobilized urease enzyme. The urea identification was achieved through the amperometric sensing of carbamic acid at a potential of $+0.35 \mathrm{~V}$, generated by the enzymatic conversion of urea. Exploring this strategy, the analytical curve presented a linear response in the range comprising $2.0 \times 10^{-4}$ to $4.0 \times 10^{-3} \mathrm{~mol} \mathrm{~L}^{-1}$, and a good correlation was verified for the biosensor response in a $0.02 \mathrm{~mol} \mathrm{~L}^{-1}$ potassium phosphate buffer solution $(\mathrm{pH}=6.5)$ in the absence and presence of milk sample. In another example, Nadifiyine et al. [78] developed a tyrosinase-based biosensor using a carbon black paste electrode matrix for the identification of phenolic species in olive oils. By using catechol as the enzymatic substrate, the amperometric response was linear of $1.3 \times 10^{-8}$ to $1.5 \times 10^{-4} \mathrm{~mol} \mathrm{~L}^{-1}$, with a limit of detection of 6.0 $\times 10^{-9} \mathrm{~mol} \mathrm{~L}^{-1}$. The applicability of the proposed biosensor was proved from the analysis of different olive oils with results statistically similar to those obtained by using a comparative Folin-Ciocalteu spectrophotometric method. In the work reported by Cammarota et al. [77], the bisphenol A was determined using a biosensor based on screen-printed electrodes (SPEs) modified with a bionanocomposite of laccase, thionine, and CB. In a previous work, the same research group reported a short communication paper demonstrating the remarkable analytical potentialities of SPEs modified with CB for the sensing of phenolic compounds (catechol, caffeic acid, gallic acid, and tyrosol) [58]. For the biosensor construction, in a first step, the SPE surface was modified with CB particles by dropping $6.0 \mu \mathrm{L}$ of $0.1 \mathrm{mg} \mathrm{mL}^{-1} \mathrm{CB}$ dispersion prepared in acetone solvent. Then, $5.0 \mu \mathrm{L}$ of $0.4 \mathrm{mmol} \mathrm{L}^{-1}$ thionine aqueous solution was added on the CB-SPE surface, which was used as the electron mediator specie. Next, the laccase enzyme was supported on the previous modified surface using $5.0 \mu \mathrm{L}$ of a laccase solution prepared with optimized enzyme units $(1.19 \mathrm{U})$. Finally, the biosensor surface was mechanically protected using a Nafion ${ }^{\circledR}$ coating.

The construction of enzymatic biosensors based on $\mathrm{CB}$ for the detection of analytes of environmental interest is a well-explored topic. Cinti et al. [54] reported a work dedicated to investigate the electrochemical sensing and biosensing performance of $\mathrm{CB}$ paste electrodes prepared with CB type N220 from Cabot Corporation (Ravenna, Italy). Regarding the electrochemical sensing studies, the proposed $\mathrm{CB}$ paste electrode showed enhanced voltammetric response toward $\left[\mathrm{Fe}(\mathrm{CN})_{6}\right]^{3-/ 4-}$ redox couple, ascorbic acid, acetaminophen, epinephrine, and 3,4-dihydroxyphenylacetic acid comparatively to a conventional carbon paste electrode prepared with graphite powder. A tyrosinase biosensor based on CB paste electrode showed remarkable analytical features toward catechol biosensing, including a sensitivity of $625 \mathrm{nA} \mu \mathrm{mol} \mathrm{L}^{-1}$ and a limit of detection of $8.0 \times 10^{-9} \mathrm{~mol} \mathrm{~L}^{-1}$. It is interesting note that these values of sensitivity and limit of detection were enhanced comparing than those obtained using carbon paste electrodes prepared with graphite, SWCNTs, and MWCNTs. We advise the reader to analyze the results presented in Table 2 by Cinti et al. [54]. In another example of CB-based sensors, Deng et al. [59] reported the preparation of a CB-based biosensor for the identification of emerging contaminants as the organophosphorus pesticides [85]. The surface of a GCE was modified with a dispersion of mesoporous carbon (MC) and CB coated with Nafion with subsequent incorporation of the organophosphorus hydrolase. The obtained biosensor was applied on the identification of paraoxon, and the amperometric response was due to the p-nitrophenol produced in the enzymatic reaction. Interestingly, through comparative assays, the authors verified that $\mathrm{MC}$ and $\mathrm{CB}$ nanoparticles provided a higher analytical sensitivity toward p-nitrophenol comparatively to an architecture designed with carbon nanotubes.

In an analogous work, Radeke et al. [28] developed an electrochemical device to monitor paraoxon exploring the SPE technology and enzymatic inhibition mechanism. In this paper, a screen-printed carbon electrode was modified 
with CB nanoparticles adopting a drop casting methodology and applied as a high performance platform for the enzyme immobilization. The paraoxon determination was performed through its inhibitory action on the butyrylcholinesterase (BChE) activity. This enzyme was immobilized on the CBSPE surface using glutaraldehyde as a crosslinking agent. The BChE-CB-SPE biosensor was exposed to paraoxon solutions during an optimized 20 min incubation time, and the analytical response was defined as the decrease of current obtained for the oxidation of the dithiobischoline dimer formation [86]. From that, the paraoxon analyte was determined in the linear concentration range of $2.0 \times 10^{-8}$ to $1.2 \times 10^{-7} \mathrm{~mol} \mathrm{~L}^{-1}$, with a limit of detection of $2.0 \times 10^{-8} \mathrm{~mol} \mathrm{~L}^{-1}$. Talarico et al. [53] proposed a biosensor based on inhibition of acetylcholinesterase (AChE) enzyme for the determination of different organophosphate and carbamate pesticides. A GCE surface was modified in a first step with a $\mathrm{CB}$ and pillar [5] arene as electron mediator, followed by the AChE enzyme using carbodiimide as linkage. Under the optimized experimental conditions, wide linear concentration ranges and very low detectability levels were obtained for the chronoamperometric identification of aldicarb, carbofuran, malaoxon, and methyl-paraoxon, as can be seen from data shown in Table 3. In addition, the analytes were quantified in spiked peanut and beetroot samples with satisfactory recoveries ranging from 86 to $121 \%$.

DET between enzymes and electrodic surfaces is an important achievement to obtain data about protein structures and mechanisms of redox reactions related to some biological and metabolic processes $[93,113,114]$. A great number of technological innovations are derived, as the development of biofuel cells, bioelectronic devices, electrochemical biosensors, among others [115]. In this scenario, the analytical determination using DET method presented is interesting because this method can be performed directly without the use of secondary molecules, as mediator species, at solution, or immobilized biocatalyst on the electrode surface [116]. However, DET is not easily achieved, because the enzyme active centre is protected by a glycoprotein shell, hindering the efficient electron tunneling [117]. In this sense, DET has been reported using nanostructured electrode architectures based on carbon nanomaterials, especially graphene derivatives $[100,101,118]$ and MWCNTs $[93,117]$. DET between CB nanoparticles and hemoglobin $(\mathrm{Hb})$ was diagnosed by the first time by Ma et al. [84], which was an important advance in the use of $\mathrm{CB}$ nanoparticles for biosensing purposes. In this interesting work, the biosensor architecture was constructed using a GCE as substrate, and this surface was modified with a casting of $\mathrm{Hb}-\mathrm{CB}$ dispersion and the mixture of $\mathrm{Hb}$ and $\mathrm{CB}$ was fixed using Nafion film. Cyclic voltammograms were recorded using the proposed $\mathrm{Hb}-\mathrm{CB} / \mathrm{GCE}$ and comparative electrodes ( $\mathrm{CB} / \mathrm{GCE}$ and $\mathrm{Hb} / \mathrm{GCE})$. The electrode containing $\mathrm{CB}$ and $\mathrm{Hb}$ showed a well-define redox pair located at -0.295 and $-0.361 \mathrm{~V}$ (versus SCE), which are attributed to the electrochemical reactions of $\mathrm{Hb}$. Authors suggest that $\mathrm{DET}$ verified for $\mathrm{Hb}$ protein on the $\mathrm{CB}$ modified electrode is due to the presence of the oxygenated functional groups and active sites on the $\mathrm{CB}$ particles surface. The bioelectrocatalytic activity of $\mathrm{Hb}$ immobilized on the $\mathrm{CB} / \mathrm{GCE}$ was explored toward the hydrogen peroxide $\left(\mathrm{H}_{2} \mathrm{O}_{2}\right)$ reduction reaction. From that, an amperometric curve was obtained for $\mathrm{H}_{2} \mathrm{O}_{2}$ concentration with a linear range between $1.0 \times 10^{-3}$ and $7.0 \times 10^{-3} \mathrm{~mol} \mathrm{~L}^{-1}$. After the work published by $\mathrm{Ma}$ et al. other authors studied the DET between CB and enzymes. Suprun et al. [119] evaluated the DET of different Fe(III)hemeproteins immobilized on electrodes modified with $\mathrm{CB}$ and didodecyldimethylammonium bromide (DDAB). The enzymatic biosensors were fabricated on a SPE surface and the DET for the following enzymes were evaluated: cytochrome $c$ (cyt $c$ ), myoglobin $(\mathrm{Mb})$, horseradish peroxidase (HRP), and cytochromes P450 (CYP 51A1, CYP 3A4, and CYP 2B4). All these hemeproteins presented a welldefined couple of redox peaks when immobilized on the proposed matrix, demonstrating the achievement of DET. Comparative assays were carried out for the disposable enzymatic biosensors constructed with SPEs modified with CB and SWCNTs. It was demonstrated that the $\mathrm{CB} / \mathrm{SPE}$ provide a better environmental for the hemeprotein immobilization, because using the SPE/SWCNT an unsatisfactory signal-tonoise ratio was registered for the measurement conducted in a supporting electrolyte solution without deoxygenation. The SPE/CB/DDAB matrix was explored in the design of an immunosensor for cardiac $\mathrm{Mb}$. The $\mathrm{cMb}$-antibodies were immobilized on a $\mathrm{CB} / \mathrm{DDAB}$ matrix. From square-wave voltammograms (SWVs) obtained for plasma samples from healthy donors and patients with acute heart attack, it was possible to verify that the proposed immunosensor was able to detect the variation of $\mathrm{cMb}$ concentration in different samples.

DET of cytochrome $\mathrm{c}$ and $\mathrm{Hb}$ biosensors designed with CB particles also were studied by Dai et al. [81] and Li et al. [83]. In the work reported by Dai et al. [81], the cytochrome P450 was entrapped on the surface of a GCE modified with a composite matrix of epoxy copolymers $\mathrm{P}$ and acetylene black. The cytochrome P450 incorporated on the proposed matrix showed electrocatalytic activity toward diethylstilbestrol. Diethylstilbestrol was amperometrically determined using the proposed biosensor in the linear concentration range from $2.0 \times 10^{-7}$ to $2.8 \times 10^{-6} \mathrm{~mol} \mathrm{~L}^{-1}$ with a limit of detection of $5.9 \times 10^{-8} \mathrm{~mol} \mathrm{~L}^{-1}$. This target analyte was successfully quantified in commercial tablet samples. In this scenario, the preparation of composite matrixes was carried out to promote DET using modified surfaces based on CB. Li et al. [83] described the synthesis of a quaternized cellulose nanoparticles (QCs)/acetylene black (AB)/enzymes. In this work, DET was verified for $\mathrm{Hb}$ and GOD enzymes. These biosensors were applied in the sensing of $\mathrm{H}_{2} \mathrm{O}_{2}$ and glucose. In a similar work, Yang et al. [80] investigated the preparation of a support matrix composed by gold nanoparticles, QCs and $\mathrm{CB}$ for immobilization of hemocyanin enzyme. The obtained enzymatic biosensor was explored in the simultaneous determination of hydroquinone and catechol in the linear ranges from $4.5 \times 10^{-7}$ to $2.4 \times 10^{-5} \mathrm{~mol} \mathrm{~L}^{-1}$ (hydroquinone) and from $3.7 \times 10^{-7}$ to $5.0 \times 10^{-5} \mathrm{~mol} \mathrm{~L}^{-1}$ (catechol), with limits of detection of $8.0 \times 10^{-9} \mathrm{~mol} \mathrm{~L}^{-1}$ and $8.7 \times 10^{-7} \mathrm{~mol} \mathrm{~L}^{-1}$ for hydroquinone and catechol, respectively. 


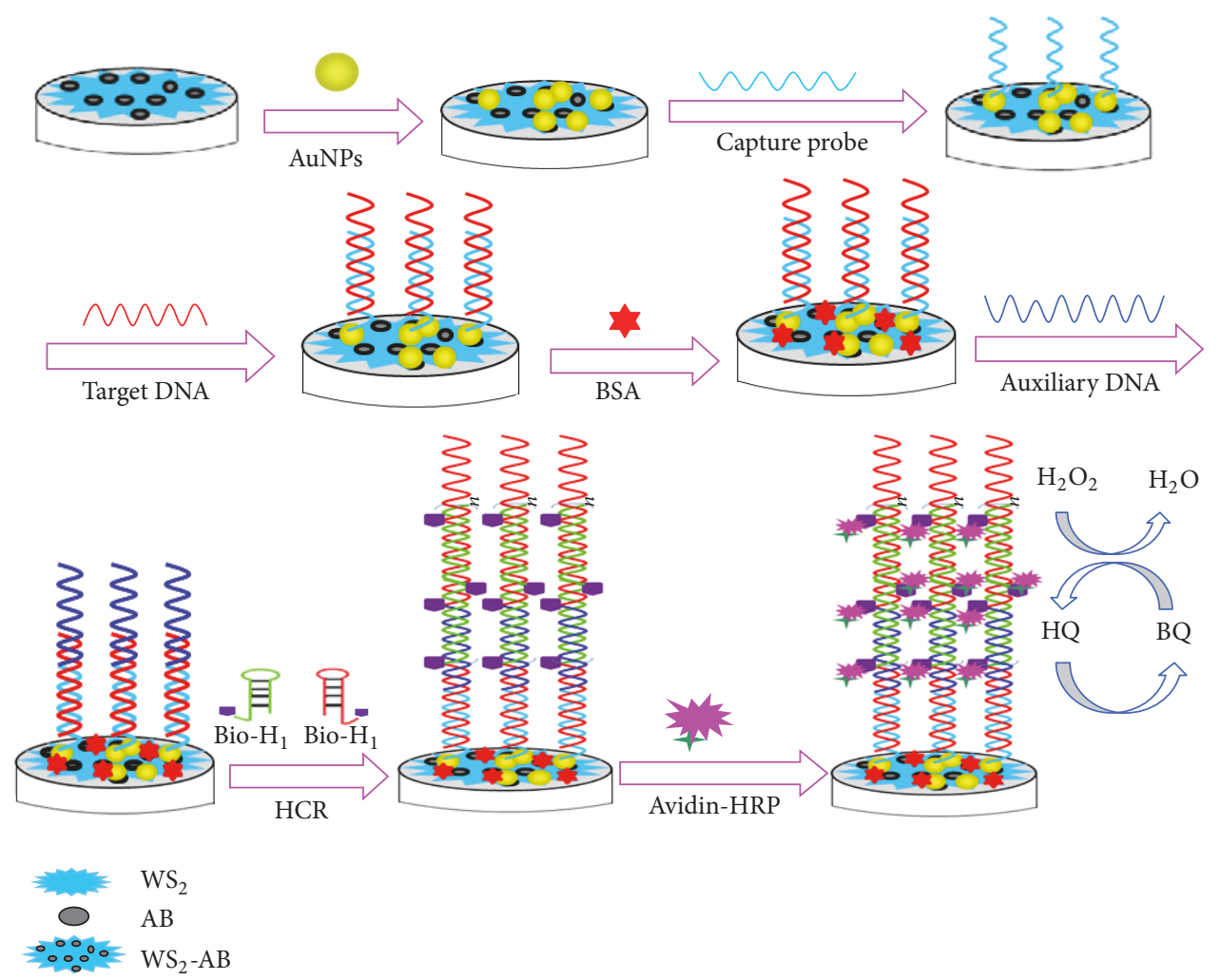

FIgURE 4: Schematic illustration of the working principle of DNA detection based on the hybridization chain reaction (reproduced with permission of The Royal Society of Chemistry [13]).

Recently, DNA biosensors based on CB were designed by Huang et al. [32] and Shuai et al. [13]. In another interesting work, Huang et al. [32] developed a new biosensor by using a combination of two-dimensional CuS nanosheets and acetylene black particles in a composite. The CuS-AB composite was synthesized by solvothermal method using ethylene glycol. For the biosensor preparation, the surface of a GCE was firstly modified with a CuS-AB film, followed by the electrodeposition of gold nanoparticles. CuS$\mathrm{AB}$ and gold nanoparticles were explored as nanomaterials of high conductivity and large electroactive surface area for the biosensor signal amplification. The quantification was defined by the decrease of peak current for the $\left[\mathrm{Fe}(\mathrm{CN})_{6}\right]^{3-/ 4-}$ redox couple after the hybridization event between the immobilized ssDNA probe and the target ssDNA. In this same research line, Shuai et al. [13] synthesized a two-dimensional tungsten disulfide-acetylene black $\left(\mathrm{WS}_{2}-\mathrm{AB}\right)$ composite by a hydrothermal method for DNA biosensing purposes. The fabrication procedure and principle of detection are schematized in Figure 4. The $\mathrm{WS}_{2}-\mathrm{AB}$ composite was deposited on a GCE surface and gold nanoparticles were electrodeposited in a following step. The authors used these two nanomaterials in the DNA biosensor preparation to ensure a large specific surface area and good electroconductivity. Exploring this strategy, the target ssDNA was determined in the range from $1.0 \times 10^{-15}$ to $1.0 \times 10^{-10} \mathrm{~mol} \mathrm{~L}^{-1}$ of the target ssDNA with a limit of detection of $1.2 \times 10^{-16} \mathrm{~mol} \mathrm{~L}^{-1}$.

\section{Conclusions and Future Perspectives}

$\mathrm{CB}$ is a very low cost nanomaterial, with relevant structural, morphological, and electronic properties for application in electrochemical sensing and biosensing. From its typical analytical sensitivity, selectivity, operational simplicity, and portability, the electrochemical biosensing routines have found a wide range of applications in different areas, including environmental, medical, biological, pharmaceutical, or industrial. The revision of literature showed that $\mathrm{CB}$ have been explored mainly in the construction of biocatalytic or enzymatic biosensors, dedicated to the determination of glucose, hydrogen peroxide, food additives, and environmental contaminants. The enhancement of the analytical performance of the proposed enzymatic biosensors is evident. A systematic comparison of the analytical features of glucose biosensors based on CB, SWCNTs, MWCNTs, graphene, GO, RGO, $\mathrm{C}_{60}$, and SWCNHs demonstrated the efficacy of $\mathrm{CB}$ as an alternative carbon nanomaterial for preparation of biosensors. Therefore, the use of $\mathrm{CB}$ in electrochemical biosensing is a relatively young research topic and a wide range of applications can be carried out. CB can be explored as support to immobilization of more complex enzymes, incorporation of antibodies and specific DNA sequences for cancer diagnostic and predisposition, and development of point-of-care devices. Moreover, from the viewpoint of material chemistry, the $\mathrm{CB}$ chemistry is versatile, and hot 
topics include the study of effect of chemical and physical treatments on the $\mathrm{CB}$ electrochemistry features, preparation of composites with different nanoparticles, and combination with ionic liquids. Researches devoted to fabrication of CBbased biosensors should be proposed in the near future, having into account topics about the use of new biosensitive interfaces, optimization of parameters, and tests in complex samples. Future applications of CB in electrochemical (bio)sensors are underway in our groups.

\section{Conflicts of Interest}

The authors declare that they have no conflicts of interest.

\section{Acknowledgments}

The authors gratefully acknowledge the Brazilian agencies CNPq (444150/2014-5), FAPESP (2015/19099-2 and 2016/12926-3), and CAPES for financial support.

\section{References}

[1] S. Iijima, "Helical microtubules of graphitic carbon," Nature, vol. 354, no. 6348, pp. 56-58, 1991.

[2] E. B. Bahadir and M. K. Sezgintürk, "Applications of graphene in electrochemical sensing and biosensing," TrAC - Trends in Analytical Chemistry, vol. 76, pp. 1-14, 2016.

[3] A. T. Lawal, "Synthesis and utilization of carbon nanotubes for fabrication of electrochemical biosensors," Materials Research Bulletin, vol. 73, pp. 308-350, 2016.

[4] P. B. Deroco, F. C. Vicentini, and O. Fatibello-Filho, "An Electrochemical Sensor for the Simultaneous Determination of Paracetamol and Codeine Using a Glassy Carbon Electrode Modified with Nickel Oxide Nanoparticles and Carbon Black," Electroanalysis, vol. 27, no. 9, pp. 2214-2220, 2015.

[5] C.-T. Li, C.-T. Lee, S.-R. Li et al., "Composite films of carbon black nanoparticles and sulfonated-polythiophene as flexible counter electrodes for dye-sensitized solar cells," Journal of Power Sources, vol. 302, pp. 155-163, 2016.

[6] F. Arduini, F. DiNardo, A. Amine, L. Micheli, G. Palleschi, and D. Moscone, "Carbon Black-Modified Screen-Printed Electrodes as Electroanalytical Tools," Electroanalysis, vol. 24, no. 4, pp. 743-751, 2012.

[7] Z.-H. Sheng, X.-Q. Zheng, J.-Y. Xu, W.-J. Bao, F.-B. Wang, and X.-H. Xia, "Electrochemical sensor based on nitrogen doped graphene: Simultaneous determination of ascorbic acid, dopamine and uric acid," Biosensors and Bioelectronics, vol. 34, no. 1, pp. 125-131, 2012.

[8] B. Habibi and M. H. Pournaghi-Azar, "Simultaneous determination of ascorbic acid, dopamine and uric acid by use of a MWCNT modified carbon-ceramic electrode and differential pulse voltammetry," Electrochimica Acta, vol. 55, no. 19, pp. 5492-5498, 2010.

[9] X. Zhang, L.-X. Ma, and Y.-C. Zhang, "Electrodeposition of platinum nanosheets on $\mathrm{C}_{60}$ decorated glassy carbon electrode as a stable electrochemical biosensor for simultaneous detection of ascorbic acid, dopamine and uric acid," Electrochimica Acta, vol. 177, Article ID 24254, pp. 118-127, 2015.

[10] S. Zhu, H. Li, W. Niu, and G. Xu, "Simultaneous electrochemical determination of uric acid, dopamine, and ascorbic acid at single-walled carbon nanohorn modified glassy carbon electrode," Biosensors and Bioelectronics, vol. 25, no. 2, pp. 940-943, 2009.

[11] F. C. Vicentini, P. A. Raymundo-Pereira, B. C. Janegitz, S. A. S. Machado, and O. Fatibello-Filho, "Nanostructured carbon black for simultaneous sensing in biological fluids," Sensors and Actuators, B: Chemical, vol. 227, pp. 610-618, 2016.

[12] T. W. B. Lo, L. Aldous, and R. G. Compton, "The use of nanocarbon as an alternative to multi-walled carbon nanotubes in modified electrodes for adsorptive stripping voltammetry," Sensors and Actuators, B: Chemical, vol. 162, no. 1, pp. 361-368, 2012.

[13] H.-L. Shuai, K.-J. Huang, and Y.-X. Chen, "A layered tungsten disulfide/acetylene black composite based DNA biosensing platform coupled with hybridization chain reaction for signal amplification," Journal of Materials Chemistry B, vol. 4, no. 6, pp. 1186-1196, 2016.

[14] B. C. Janegitz, M. Baccarin, P. A. Raymundo-Pereira et al., "The use of dihexadecylphosphate in sensing and biosensing," Sensors and Actuators, B: Chemical, vol. 220, pp. 805-813, 2015.

[15] B. C. Janegitz, J. Cancino, and V. Zucolotto, "Disposable biosensors for clinical diagnosis," Journal of Nanoscience and Nanotechnology, vol. 14, no. 1, pp. 378-389, 2014.

[16] F. Fabry, G. Flamant, and L. Fulcheri, "Carbon black processing by thermal plasma. Analysis of the particle formation mechanism," Chemical Engineering Science, vol. 56, no. 6, pp. 21232132, 2001.

[17] C. M. Long, M. A. Nascarella, and P. A. Valberg, "Carbon black vs. black carbon and other airborne materials containing elemental carbon: Physical and chemical distinctions," Environmental Pollution, vol. 181, pp. 271-286, 2013.

[18] M. Hindermann-Bischoff and F. Ehrburger-Dolle, "Electrical conductivity of carbon black-polyethylene composites. Experimental evidence of the change of cluster connectivity in the PTC effect," Carbon, vol. 39, no. 3, pp. 375-382, 2001.

[19] P. E. Khizhnyak, A. V. Chechetkin, and A. P. Glybin, “Thermal conductivity of carbon black," Journal of Engineering Physics, vol. 37, no. 3, pp. 1073-1075, 1979.

[20] Y. Fukahori, "Generalized concept of the reinforcement of elastomers. Part 1: Carbon black reinforcement of rubbers," Rubber Chemistry and Technology, vol. 80, no. 4, pp. 701-725, 2007.

[21] W. Smith, F. Thornhill, and R. Bray, "Surface area and properties of carbon black,' Industrial Engineering Chemistry, vol. 33, no. 10, pp. 1303-1307, 1941.

[22] J. H. Atkins, "Porosity and surface area of carbon black," Carbon, vol. 3, no. 3, pp. 299-303, 1965.

[23] B. P. Holownia, "Effect of carbon black on poisson's ratio of elastomers," Rubber Chemistry and Technology, vol. 48, no. 2, pp. 246-253, 1975.

[24] R. Xu, C. Wu, and H. Xu, "Particle size and zeta potential of carbon black in liquid media," Carbon, vol. 45, no. 14, pp. 28062809, 2007.

[25] S. Kohjiya, A. Katoh, T. Suda, J. Shimanuki, and Y. Ikeda, "Visualisation of carbon black networks in rubbery matrix by skeletonisation of 3D-TEM image," Polymer, vol. 47, no. 10, pp. 3298-3301, 2006.

[26] P. A. Thrower, Chemistry and Physics of Carbon, vol. 24, New York, NY, USA, 1993, CRC Press.

[27] L. R. Radovic, Chemistry Physics of Carbon, vol. 27, CRC Press, New York, NY, USA, 2000. 
[28] K. H. Radeke, K. O. Backhaus, and A. Swiatkowski, "Electrical conductivity of activated carbons," Carbon, vol. 29, no. 1, pp. 122123, 1991.

[29] J.-P. Reboul and G. Moussalli, "About Some D-C Conduction Processes in Carbon Black Filled Polymers," International Journal of Polymeric Materials and Polymeric Biomaterials, vol. 5, no. 1-2, pp. 133-146, 1976.

[30] I. Balberg, N. Wagner, Y. Goldstein, and S. Z. Weisz, "Tunneling and percolation behavior in granular metals," MRS Proceedings, vol. 195, 2011.

[31] F. Arduini, M. Forchielli, A. Amine et al., "Screen-printed biosensor modified with carbon black nanoparticles for the determination of paraoxon based on the inhibition of butyrylcholinesterase," Microchimica Acta, vol. 182, no. 3-4, pp. 643651, 2014.

[32] K.-J. Huang, Y.-J. Liu, J.-Z. Zhang, and Y.-M. Liu, "A sequencespecific DNA electrochemical sensor based on acetylene black incorporated two-dimensional $\mathrm{CuS}$ nanosheets and gold nanoparticles," Sensors and Actuators, B: Chemical, vol. 209, pp. 570-578, 2015.

[33] G. A. Posthuma-Trumpie, J. H. Wichers, M. Koets, L. B. J. M. Berendsen, and A. Van Amerongen, "Amorphous carbon nanoparticles: A versatile label for rapid diagnostic (immuno)assays," Analytical and Bioanalytical Chemistry, vol. 402, no. 2, pp. 593-600, 2012.

[34] X. Dang, C. Hu, Y. Wei, W. Chen, and S. Hu, "Sensitivity improvement of the oxidation of tetracycline at acetylene black electrode in the presence of sodium dodecyl sulfate," Electroanalysis, vol. 16, no. 23, pp. 1949-1955, 2004.

[35] H. Zhang, "Preparation of an acetylene black-dihexadecyl hydrogen phosphate composite film modified glassy carbon electrode and the application in the determination of hydroxycamptothecin in blood serum," Journal of Membrane Science, vol. 251, no. 1-2, pp. 43-49, 2005.

[36] H. Zhang, "Electrochemistry and voltammetric determination of colchicine using an acetylene black-dihexadecyl hydrogen phosphate composite film modified glassy carbon electrode," Bioelectrochemistry, vol. 68, no. 2, pp. 197-201, 2006.

[37] F. C. Vicentini, A. E. Ravanini, L. C. S. Figueiredo-Filho, J. Iniesta, C. E. Banks, and O. Fatibello-Filho, "Imparting improvements in electrochemical sensors: Evaluation of different carbon blacks that give rise to significant improvement in the performance of electroanalytical sensing platforms," Electrochimica Acta, vol. 157, pp. 125-133, 2015.

[38] J. Song, J. Yang, J. Zeng, J. Tan, and L. Zhang, "Acetylene black nanoparticle-modified electrode as an electrochemical sensor for rapid determination of rutin," Microchimica Acta, vol. 171, no. 3, pp. 283-287, 2010.

[39] R. Wang, K. Wu, and C. Wu, "Highly sensitive electrochemical sensor for toxic ractopamine based on the enhancement effect of acetylene black nanoparticles," Analytical Methods, vol. 7, no. 19, pp. 8069-8077, 2015.

[40] L. Lu, F. Zhang, J. Xia, Z. Wang, X. Liu, and Y. Yuan, "Conductive carbon black-graphene composite for sensitive sensing of rutin," International Journal of Electrochemical Science, vol. 10, no. 2, pp. 1646-1657, 2015.

[41] Y. Huang, H. Yan, and Y. Tong, "Electrocatalytic determination of Reduced Glutathione using rutin as a mediator at acetylene black spiked carbon paste electrode," Journal of Electroanalytical Chemistry, vol. 743, pp. 25-30, 2015.

[42] S. I. R. Malha, A. A. Lahcen, F. Arduini, A. Ourari, and A. Amine, "Electrochemical Characterization of Carbon Solid-like
Paste Electrode Assembled Using Different Carbon Nanoparticles," Electroanalysis, vol. 28, no. 5, pp. 1044-1051, 2016.

[43] A. Ait Lahcen, S. Ait Errayess, and A. Amine, "Voltammetric determination of sulfonamides using paste electrodes based on various carbon nanomaterials," Microchimica Acta, vol. 183, no. 7, pp. 2169-2176, 2016.

[44] C. Hou, W. Tang, C. Zhang, Y. Wang, and N. Zhu, "A novel and sensitive electrochemical sensor for bisphenol A determination based on carbon black supporting ferroferric oxide nanoparticles," Electrochimica Acta, vol. 144, pp. 324-331, 2014.

[45] P. Deng, Z. Xu, J. Li, and Y. Kuang, "Acetylene black paste electrode modified with a molecularly imprinted chitosan film for the detection of bisphenol A," Microchimica Acta, vol. 180, no. 9-10, pp. 861-869, 2013.

[46] I. G. Svegl, M. Bele, and B. Ogorevc, "Carbon black nanoparticles film electrode prepared by using substrate-induced deposition approach," Analytica Chimica Acta, vol. 628, no. 2, pp. 173180, 2008.

[47] C. Tan, X. Xu, F. Wang, Z. Li, J. Liu, and J. Ji, "Carbon black supported ultra-high loading silver nanoparticle catalyst for electro-oxidation and determination of hydrazine," Science China Chemistry, vol. 56, no. 7, pp. 911-916, 2013.

[48] P.-H. Deng, J.-J. Fei, and Y.-L. Feng, "Determination of trace vanadium $(\mathrm{V})$ by adsorptive anodic stripping voltammetry on an acetylene black paste electrode in the presence of alizarin violet," Journal of Electroanalytical Chemistry, vol. 648, no. 2, pp. 85-91, 2010.

[49] P. Deng, Z. Xu, and Y. Kuang, "Electrochemically reduced graphene oxide modified acetylene black paste electrode for the sensitive determination of bisphenol A," Journal of Electroanalytical Chemistry, vol. 707, pp. 7-14, 2013.

[50] W. Huang, W. Qu, and D. Zhu, "Electrochemistry and determination of 1-naphthylacetic acid using an acetylene black film modified electrode," Bulletin of the Korean Chemical Society, vol. 29, no. 7, pp. 1323-1326, 2008.

[51] S. Cinti, F. Santella, D. Moscone, and F. Arduini, " $\mathrm{Hg}^{2+}$ detection using a disposable and miniaturized screen-printed electrode modified with nanocomposite carbon black and gold nanoparticles," Environmental Science and Pollution Research, vol. 23, no. 9, pp. 8192-8199, 2016.

[52] S. Cinti, D. Neagu, M. Carbone, I. Cacciotti, D. Moscone, and F. Arduini, "Novel carbon black-cobalt phthalocyanine nanocomposite as sensing platform to detect organophosphorus pollutants at screen-printed electrode," Electrochimica Acta, vol. 188, pp. 574-581, 2016.

[53] D. Talarico, S. Cinti, F. Arduini, A. Amine, D. Moscone, and G. Palleschi, "Phosphate detection through a cost-effective carbon black nanoparticle-modified screen-printed electrode embedded in a continuous flow system," Environmental Science and Technology, vol. 49, no. 13, pp. 7934-7939, 2015.

[54] S. Cinti, S. Politi, D. Moscone, G. Palleschi, and F. Arduini, "Stripping Analysis of As(III) by means of screen-printed electrodes modified with gold nanoparticles and carbon black nanocomposite," Electroanalysis, vol. 26, no. 5, pp. 931-939, 2014.

[55] Y. Tan, J. Jin, S. Zhang et al., "Electrochemical Determination of Bisphenol A Using a Molecularly Imprinted Chitosan-acetylene Black Composite Film Modified Glassy Carbon Electrode," Electroanalysis, vol. 28, no. 1, pp. 189-196, 2016.

[56] D. Talarico, F. Arduini, A. Amine, D. Moscone, and G. Palleschi, "Screen-printed electrode modified with carbon black nanoparticles for phosphate detection by measuring the electroactive 
phosphomolybdate complex," Talanta, vol. 141, pp. 267-272, 2015.

[57] A. Ghanam, A. A. Lahcen, and A. Amine, "Electroanalytical determination of Bisphenol A: investigation of electrode surface fouling using various carbon materials," Journal of Electroanalytical Chemistry, vol. 789, pp. 58-66, 2017.

[58] D. Talarico, F. Arduini, A. Constantino et al., "Carbon black as successful screen-printed electrode modifier for phenolic compound detection," Electrochemistry Communications, vol. 60, pp. 78-82, 2015.

[59] P. Deng, J. Fei, J. Zhang, and Y. Feng, "Determination of molybdenum by adsorptive anodic stripping voltammetry of molybdenum-alizarin violet complex at an acetylene black paste electrode," Food Chemistry, vol. 124, no. 3, pp. 1231-1237, 2011.

[60] L. Wang and L. Xu, "Cyclic voltammetric determination of free and total sulfite in muscle foods using an acetylferrocenecarbon black-poly(vinyl butyral) modified glassy carbon electrode," Journal of Agricultural and Food Chemistry, vol. 62, no. 42, pp. 10248-10253, 2014.

[61] S. I. R. Malha, J. Mandli, A. Ourari, and A. Amine, "Carbon black-modified electrodes as sensitive tools for the electrochemical detection of nitrite and nitrate," Electroanalysis, vol. 25, no. 10, pp. 2289-2297, 2013.

[62] P. Xie, X. Chen, F. Wang, C. Hu, and S. Hu, "Electrochemical behaviors of adrenaline at acetylene black electrode in the presence of sodium dodecyl sulfate," Colloids and Surfaces B: Biointerfaces, vol. 48, no. 1, pp. 17-23, 2006.

[63] X. Zhou, K. He, Y. Wang, H. Zheng, and S.-I. Suye, "Amperometric determination of ascorbic acid on an au electrode modified by a composite film of poly(3,4-ethylenedioxythiophene) and superconductive carbon black," Analytical Sciences, vol. 31, no. 5, pp. 429-436, 2015.

[64] R. M. Abdel Hameed, "Amperometric glucose sensor based on nickel nanoparticles/carbon Vulcan XC-72R," Biosensors and Bioelectronics, vol. 47, pp. 248-257, 2013.

[65] Q. Zhang, H. Huang, and X. Liu, "An ultrasensitive electrochemical sensor for xanthine and hypoxanthine based on the enhancement effect of acetylene black," Analytical Methods, vol. 6, no. 20, pp. 8200-8206, 2014.

[66] C. Zanardi, E. Ferrari, L. Pigani, F. Arduini, R. Seeber, and M. Ongar, "Development of an Electrochemical Sensor for NADH Determination Based on a Caffeic Acid Redox Mediator Supported on Carbon Black," Chemosensors, vol. 3, no. 2, p. 118, 2015.

[67] L.-N. Wu, Y.-L. Tan, L. Wang et al., "Dopamine sensor based on a hybrid material composed of cuprous oxide hollow microspheres and carbon black," Microchimica Acta, vol. 182, no. 7, pp. 1361-1369, 2015.

[68] F. Arduini, C. Zanardi, S. Cinti et al., "Effective electrochemical sensor based on screen-printed electrodes modified with a carbon black-Au nanoparticles composite," Sensors and Actuators, B: Chemical, vol. 212, pp. 536-543, 2015.

[69] L. Lin, C. Song, L. Xie et al., "Electrochemical determination of xanthine and hypoxanthine in rat striatum with an acetylene black-dihexadecyl hydrogen phosphate composite film modified electrode by HPLC coupled with in vivo microdialysis," Microchimica Acta, vol. 170, no. 1, pp. 47-52, 2010.

[70] L. Mei, P. Zhang, J. Chen et al., "Non-enzymatic sensing of glucose and hydrogen peroxide using a glassy carbon electrode modified with a nanocomposite consisting of nanoporous copper, carbon black and nafion," Microchimica Acta, vol. 183, no. 4, pp. 1359-1365, 2016.
[71] R. C. Carvalho, A. Mandil, K. P. Prathish, A. Amine, and C. M. A. Brett, "Carbon nanotube, carbon black and copper nanoparticle modified screen printed electrodes for amino acid determination," Electroanalysis, vol. 25, no. 4, pp. 903-913, 2013.

[72] T. A. Silva, H. Zanin, E. Saito et al., "Electrochemical behaviour of vertically aligned carbon nanotubes and graphene oxide nanocomposite as electrode material," Electrochimica Acta, vol. 119, pp. 114-119, 2014.

[73] T. A. Silva, H. Zanin, E. J. Corat, P. W. May, and O.-F. Filho, "Preparation and electroanalytical applications of vertically aligned carbon nanotubes," in Electrochemistry, C. Banks, R. Mortimer, and S. McIntosh, Eds., vol. 13, pp. 50-96, Royal Society of Chemistry, Cambridge, UK, London, 2015.

[74] A. Liu, K. Wang, S. Weng et al., "Development of electrochemical DNA biosensors," TrAC - Trends in Analytical Chemistry, vol. 37, pp. 101-111, 2012.

[75] K. K. Mistry, K. Layek, A. Mahapatra, C. RoyChaudhuri, and H. Saha, "A review on amperometric-type immunosensors based on screen-printed electrodes," Analyst, vol. 139, no. 10, pp. 22892311, 2014.

[76] R. V. Shamagsumova, D. N. Shurpik, P. L. Padnya, I. I. Stoikov, and G. A. Evtugyn, "Acetylcholinesterase biosensor for inhibitor measurements based on glassy carbon electrode modified with carbon black and pillar 5 arene," Talanta, vol. 144, Article ID 15773, pp. 559-568, 2015.

[77] M. Portaccio, D. Di Tuoro, F. Arduini et al., "Laccase biosensor based on screen-printed electrode modified withthioninecarbon black nanocomposite, for Bisphenol A detection," Electrochimica Acta, vol. 109, pp. 340-347, 2013.

[78] S. Nadifiyine, M. Haddam, J. Mandli et al., "Amperometric Biosensor Based on Tyrosinase Immobilized on to a Carbon Black Paste Electrode for Phenol Determination in Olive Oil," Analytical Letters, vol. 46, no. 17, pp. 2705-2726, 2013.

[79] F. Arduini, F. Di Giorgio, A. Amine, F. Cataldo, D. Moscone, and G. Palleschi, "Electroanalytical characterization of carbon black nanomaterial paste electrode: Development of highly sensitive tyrosinase biosensor for catechol detection," Analytical Letters, vol. 43, no. 10-11, pp. 1688-1702, 2010.

[80] P. Yang, J. You, F. Li et al., "Electrochemical biosensing platform based on a hemocyanin-Au@QC NP-carbon black hybrid nano-composite film," Analytical Methods, vol. 5, no. 13, pp. 3168-3171, 2013.

[81] C. Dai, Y. Ding, M. Li, and J. Fei, "Direct electrochemistry of cytochrome P450 in a biocompatible film composed of an epoxy polymer and acetylene black," Microchimica Acta, vol. 176, no. 3-4, pp. 397-404, 2012.

[82] Y. Xiao-He, Y. Qiang, Y. Hao, W. Li, and C. Yu-Quan, "Performance and Mechanism of Screen-Printed Carbon Paste Electrode Glucose Biosensors Based on Functional Carbon Black," Chinese Journal of Analytical Chemistry, vol. 35, no. 12, pp. 1751-1755, 2007.

[83] M. Li, Y. Qi, Y. Ding, Q. Zhao, J. Fei, and J. Zhou, "Electrochemical sensing platform based on the quaternized cellulose nanoparticles/acetylene black/enzymes composite film," Sensors and Actuators, B: Chemical, vol. 168, pp. 329-335, 2012.

[84] G.-X. Ma, T.-H. Lu, and Y.-Y. Xia, "Direct electrochemistry and bioelectrocatalysis of hemoglobin immobilized on carbon black," Bioelectrochemistry, vol. 71, no. 2, pp. 180-185, 2007.

[85] J. H. Lee, J. Y. Park, K. Min, H. J. Cha, S. S. Choi, and Y. J. Yoo, "A novel organophosphorus hydrolase-based biosensor using mesoporous carbons and carbon black for the detection 
of organophosphate nerve agents," Biosensors and Bioelectronics, vol. 25, no. 7, pp. 1566-1570, 2010.

[86] I. Bourais, S. Maliki, H. Mohammadi, and A. Amine, "Investigation of sulfonamides inhibition of carbonic anhydrase enzyme using multiphotometric and electrochemical techniques," Enzyme and Microbial Technology, vol. 96, pp. 23-29, 2017.

[87] V. Laurinavicius, J. Razumiene, and V. Gureviciene, "Bioelectrochemical conversion of urea on carbon black electrode and application," IEEE Sensors Journal, vol. 13, no. 6, pp. 2208-2213, 2013.

[88] J. Wang, "Electrochemical glucose biosensors," Chemical Reviews, vol. 108, no. 2, pp. 814-825, 2008.

[89] S.-N. Liu, Y.-J. Yin, and C.-X. Cai, "Immobilization and characterization of glucose oxidase on single-walled carbon nanotubes and its application to sensing glucose," Chinese Journal of Chemistry, vol. 25, no. 4, pp. 439-447, 2007.

[90] M. Raicopol, A. Prună, C. Damian, and L. Pilan, "Functionalized single-walled carbon nanotubes/polypyrrole composites for amperometric glucose biosensors," Nanoscale Research Letters, vol. 8, no. 1, pp. 1-8, 2013.

[91] Y. Zhou, H. Yang, and H.-Y. Chen, "Direct electrochemistry and reagentless biosensing of glucose oxidase immobilized on chitosan wrapped single-walled carbon nanotubes," Talanta, vol. 76, no. 2, pp. 419-423, 2008.

[92] Y. Liu, M. Wang, F. Zhao, Z. Xu, and S. Dong, "The direct electron transfer of glucose oxidase and glucose biosensor based on carbon nanotubes/chitosan matrix," Biosensors and Bioelectronics, vol. 21, no. 6, pp. 984-988, 2005.

[93] B. C. Janegitz, R. Pauliukaite, M. E. Ghica, C. M. A. Brett, and O. Fatibello-Filho, "Direct electron transfer of glucose oxidase at glassy carbon electrode modified with functionalized carbon nanotubes within a dihexadecylphosphate film," Sensors and Actuators, B: Chemical, vol. 158, no. 1, pp. 411-417, 2011.

[94] C. Deng, J. Chen, X. Chen, C. Xiao, L. Nie, and S. Yao, "Direct electrochemistry of glucose oxidase and biosensing for glucose based on boron-doped carbon nanotubes modified electrode," Biosensors and Bioelectronics, vol. 23, no. 8, pp. 1272-1277, 2008.

[95] S. Deng, G. Jian, J. Lei, Z. Hu, and H. Ju, "A glucose biosensor based on direct electrochemistry of glucose oxidase immobilized on nitrogen-doped carbon nanotubes," Biosensors and Bioelectronics, vol. 25, no. 2, pp. 373-377, 2009.

[96] Y.-F. Gao, T. Yang, X.-L. Yang et al., "Direct electrochemistry of glucose oxidase and glucose biosensing on a hydroxyl fullerenes modified glassy carbon electrode," Biosensors and Bioelectronics, vol. 60, pp. 30-34, 2014.

[97] B. Thirumalraj, S. Palanisamy, S.-M. Chen, C.-Y. Yang, P. Periakaruppan, and B.-S. Lou, "Direct electrochemistry of glucose oxidase and sensing of glucose at a glassy carbon electrode modified with a reduced graphene oxide/fullerene$\mathrm{C}_{60}$ composite," RSC Advances, vol. 5, no. 95, pp. 77651-77657, 2015.

[98] L.-H. Lin and J.-S. Shih, "Immobilized fullerene $\mathrm{C}_{60}$-enzymebased electrochemical glucose sensor," Journal of the Chinese Chemical Society, vol. 58, no. 2, pp. 228-235, 2011.

[99] P. Wu, Q. Shao, Y. Hu et al., "Direct electrochemistry of glucose oxidase assembled on graphene and application to glucose detection," Electrochimica Acta, vol. 55, no. 28, pp. 8606-8614, 2010.

[100] X. Kang, J. Wang, H. Wu, I. A. Aksay, J. Liu, and Y. Lin, "Glucose oxidase-graphene-chitosan modified electrode for direct electrochemistry and glucose sensing," Biosensors and Bioelectronics, vol. 25, no. 4, pp. 901-905, 2009.

[101] C. Shan, H. Yang, J. Song, D. Han, A. Ivaska, and L. Niu, “Direct electrochemistry of glucose oxidase and biosensing for glucose based on graphene," Analytical Chemistry, vol. 81, no. 6, pp. 2378-2382, 2009.

[102] K. Wang, Q. Liu, Q.-M. Guan, J. Wu, H.-N. Li, and J.-J. Yan, "Enhanced direct electrochemistry of glucose oxidase and biosensing for glucose via synergy effect of graphene and CdS nanocrystals," Biosensors and Bioelectronics, vol. 26, no. 5, pp. 2252-2257, 2011.

[103] Q. Zhang, S. Wu, L. Zhang et al., "Fabrication of polymeric ionic liquid/graphene nanocomposite for glucose oxidase immobilization and direct electrochemistry," Biosensors and Bioelectronics, vol. 26, no. 5, pp. 2632-2637, 2011.

[104] S. Palanisamy, S. Cheemalapati, and S.-M. Chen, "Amperometric glucose biosensor based on glucose oxidase dispersed in multiwalled carbon nanotubes/graphene oxide hybrid biocomposite," Materials Science and Engineering C, vol. 34, no. 1, pp. 207-213, 2014.

[105] J. D. Qiu, J. Huang, and R. P. Liang, "Nanocomposite film based on graphene oxide for high performance flexible glucose biosensor," Sensors and Actuators B: Chemical, vol. 160, no. 1, pp. 287-294, 2011.

[106] Y. Jiang, Q. Zhang, F. Li, and L. Niu, "Glucose oxidase and graphene bionanocomposite bridged by ionic liquid unit for glucose biosensing application," Sensors and Actuators, B: Chemical, vol. 161, no. 1, pp. 728-733, 2012.

[107] B. Unnikrishnan, S. Palanisamy, and S.-M. Chen, "A simple electrochemical approach to fabricate a glucose biosensor based on graphene-glucose oxidase biocomposite," Biosensors and Bioelectronics, vol. 39, no. 1, pp. 70-75, 2013.

[108] A. A. Sehat, A. A. Khodadadi, F. Shemirani, and Y. Mortazavi, "Fast immobilization of glucose oxidase on graphene oxide for highly sensitive glucose biosensor fabrication," International Journal of Electrochemical Science, vol. 10, no. 20145, pp. 272286, 2015.

[109] V. Mani, B. Devadas, and S.-M. Chen, "Direct electrochemistry of glucose oxidase at electrochemically reduced graphene oxide-multiwalled carbon nanotubes hybrid material modified electrode for glucose biosensor," Biosensors and Bioelectronics, vol. 41, no. 1, pp. 309-315, 2013.

[110] B. Liang, L. Fang, G. Yang, Y. Hu, X. Guo, and X. Ye, "Direct electron transfer glucose biosensor based on glucose oxidase selfassembled on electrochemically reduced carboxyl graphene," Biosensors and Bioelectronics, vol. 43, no. 1, pp. 131-136, 2013.

[111] S. Palanisamy, C. Karuppiah, and S.-M. Chen, "Direct electrochemistry and electrocatalysis of glucose oxidase immobilized on reduced graphene oxide and silver nanoparticles nanocomposite modified electrode," Colloids and Surfaces B: Biointerfaces, vol. 114, pp. 164-169, 2014.

[112] X. Liu, L. Shi, W. Niu, H. Li, and G. Xu, "Amperometric glucose biosensor based on single-walled carbon nanohorns," Biosensors and Bioelectronics, vol. 23, no. 12, pp. 1887-1890, 2008.

[113] A. L. Ghindilis, P. Atanasov, and E. Wilkins, "Enzyme-Catalyzed Direct Electron Transfer: Fundamentals and Analytical Applications," Electroanalysis, vol. 9, no. 9, pp. 661-674, 1997.

[114] C. Cai and J. Chen, "Direct electron transfer of glucose oxidase promoted by carbon nanotubes," Analytical Biochemistry, vol. 332, no. 1, pp. 75-83, 2004.

[115] R. S. Freire, C. A. Pessoa, L. D. Mello, and L. T. Kubota, "Direct electron transfer: an approach for electrochemical biosensors 
with higher selectivity and sensitivity," Journal of the Brazilian Chemical Society, vol. 14, no. 2, pp. 230-243, 2003.

[116] A. Ghindilis, "Direct electron transfer catalysed by enzymes: Application for biosensor development," Biochemical Society Transactions, vol. 28, no. 2, pp. 84-89, 2000.

[117] M. Wooten, S. Karra, M. Zhang, and W. Gorski, "On the direct electron transfer, sensing, and enzyme activity in the glucose oxidase/carbon nanotubes system," Analytical Chemistry, vol. 86, no. 1, pp. 752-757, 2014.

[118] B. Liang, X. Guo, L. Fang et al., "Study of direct electron transfer and enzyme activity of glucose oxidase on graphene surface," Electrochemistry Communications, vol. 50, pp. 1-5, 2015.

[119] E. V. Suprun, F. Arduini, D. Moscone, G. Palleschi, V. V. Shumyantseva, and A. I. Archakov, "Direct Electrochemistry of Heme Proteins on Electrodes Modified with Didodecyldimethyl Ammonium Bromide and Carbon Black," Electroanalysis, vol. 24, no. 10, pp. 1923-1931, 2012. 

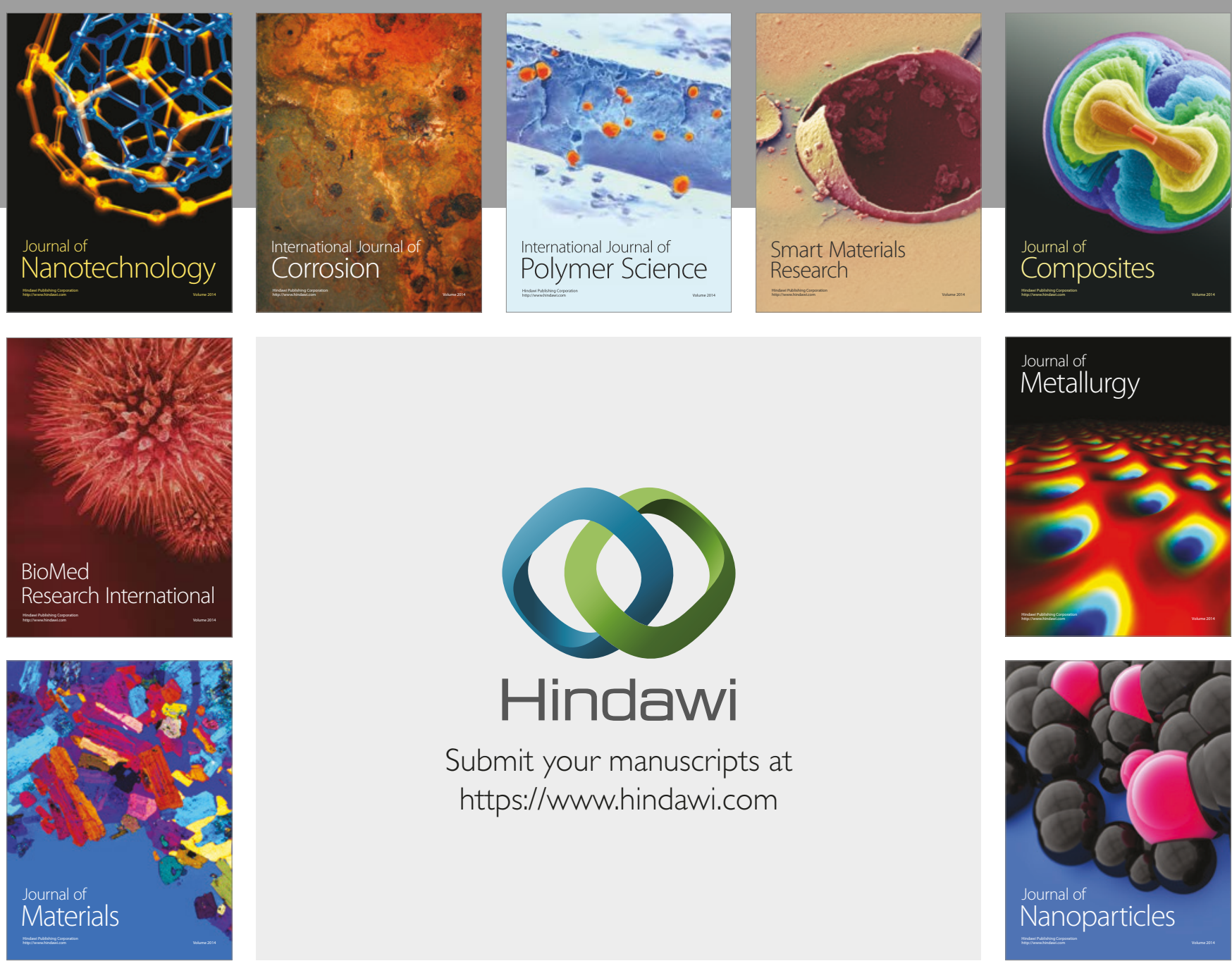

\section{Hindawi}

Submit your manuscripts at

https://www.hindawi.com
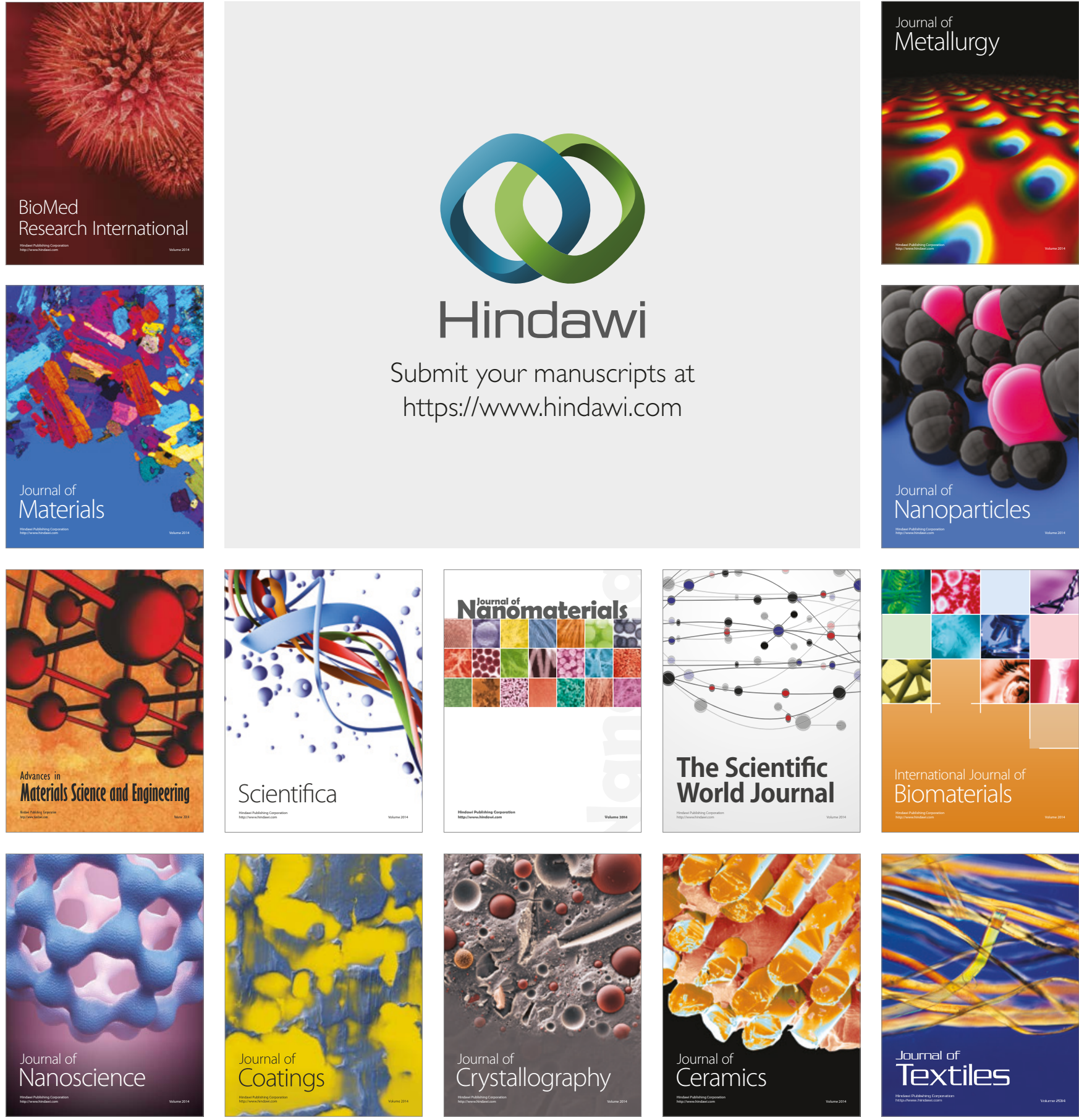

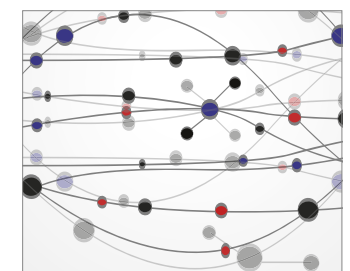

The Scientific World Journal
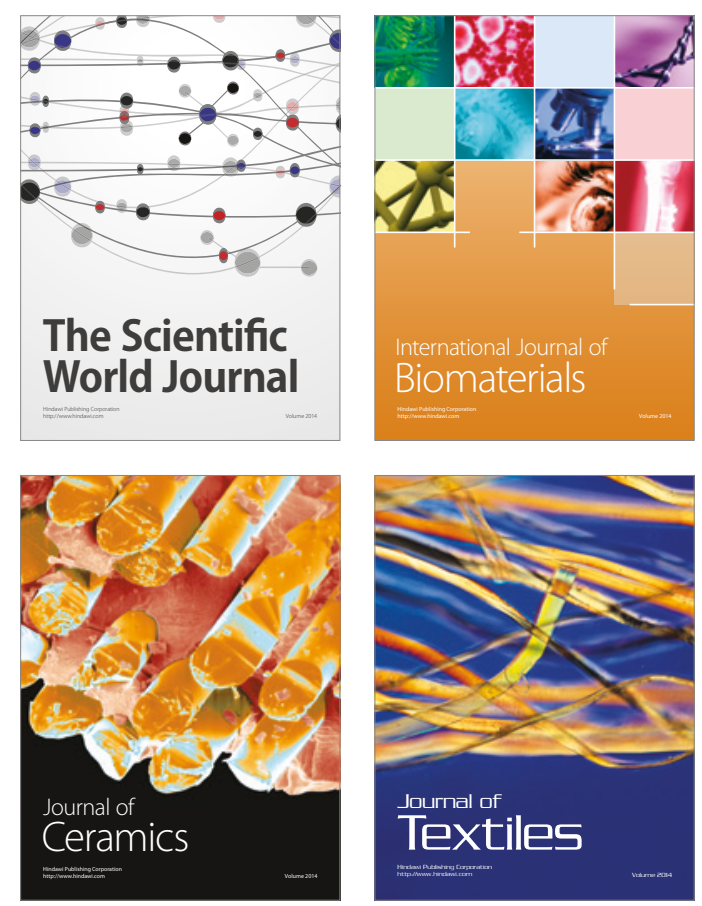